\title{
The GEBCO and NOAA Chart Adequacy Workshop
}

\author{
Cecilia Z. Cortina G. ${ }^{a, b}$, Rochelle Wigley ${ }^{b}$, Shachak Pe'eri ${ }^{c}$ \\ ${ }^{a}$ SEMAR,Veracruz,Veracruz-Llave, Mexico (cecilia.cortina@gmail.com) \\ ${ }^{b}$ GEBCO, University of New Hampshire, Durham, NH, U.S.A. (rochelle@ccom.unh.edu) \\ ${ }^{c} N O A A$, Office of Coast Survey, MD, U.S.A. (Shachak.Peeri@NOAA.gov) \\ * Corresponding author: Cecilia Z. Cortina (cecilia.cortina@gmail.com)
}

Keywords: Marine Cartography, Building Capacity, Education, Nautical Charts

\begin{abstract}
:
On July 23, NOAA Coast Survey hosted a three-day Chart Adequacy Workshop that included participants from 13 countries. This is the fourth Chart Adequacy Workshop held at National Oceanic and Atmospheric Administration's (NOAA) Silver Spring, Maryland campus. This was the fourth workshop hosted by NOAA and Nippon Foundation / General Bathymetric Chart of the Oceans (GEBCO) Training Program at the Center for Coastal and Ocean Mapping, UNH. Unlike previous years $(2017,2016,2015)$, the focus of this week was on networking and support for the upcoming International Cartographic Association (ICA) Working Group on Marine Cartography meeting held on July 26 and in preparation for next year's International Cartographic Conference (ICC).
\end{abstract}

The main goal of the workshop is to provide training for professional cartographers and hydrographers on techniques for assessing nautical chart adequacy using publicly-available information, such as satellite images and maritime automatic identification system (AIS) data. The participants received an overview on Coast Survey datasets, processes, and requirements for nautical charts. They also learned about pre-processing hydrographic data, such as loading charts, uploading imagery, and applying electronic navigation charts (ENCs) and AIS point data. Through a series of lab units, the attendees practiced performing the concepts they learned.

The 2018 participants were from Australia, Greece, Ireland, Japan, Latvia, Madagascar, Mexico, Nigeria, Peru, Poland, St. Vincent and the Grenadines, Taiwan, and Trinidad and Tobago. The international nature of the event allows the participants to meet and learn from cartographers from a variety of backgrounds and expertises. The individuals include Nippon Foundation / GEBCO training program students and those nominated by their home hydrographic offices and their travel was sponsored through funds secured by the workshop organizers.

The workshop was developed in part to address the need to improve the collection, quality, and availability of hydrographic data world-wide, and increase the standardization of chart adequacy evaluations across the globe. Coast Survey is currently working with the International Hydrographic Organization (IHO) to recommend participants for next year's workshop towards the of July, 2019. 